Article

\title{
Gender Muddle: Reply to Dembroff
}

\author{
Alex Byrne \\ Department of Linguistics and Philosophy, Massachusetts Institute of Technology; \\ abyrne@mit.edu
}

Submitted: 15 September 2020, accepted: 7 March 2021, published: 25 April 2021

\begin{abstract}
Robin Dembroff's "Escaping the natural attitude about gender" replies to my "Are women adult human females?". This paper responds to Dembroff's many criticisms of my arguments, as well as to the charge that "Are women...?" "fundamentally is an unscholarly attempt to vindicate a political slogan that is currently being used to undermine civic rights and respect for trans persons". I argue that Dembroff's criticisms fail without exception, and explain why the claims about my motives are baseless.
\end{abstract}

Keywords: gender; sex; transgender

How to cite: Byrne, A. Gender Muddle: Reply to Dembroff. Journal of Controversial Ideas 2021, 1(1), 5; doi:10.35995/jci01010005.

(C) 2021 Copyright by the author. This article is an open access article distributed under the terms and conditions of the Creative Commons Attribution (CC BY 4.0) license.

(c) (i)

Philosophers often seem to think that they can just 'assign' any meaning whatever to any word; and so no doubt, in an absolutely trivial sense, they can (like Humpty-Dumpty).

\section{J. L. Austin, Sense and Sensibilia}

It will come as no surprise to those who have been following the recent turmoil in philosophy over sex and gender that "Are women adult human females?" (henceforth Are women ... ?) was not a hit with a number of anonymous referees. ${ }^{1}$ For example, the report of "Referee 1" for a top journal read in its entirety as follows:

This paper should not be accepted. The arguments given in favor of the author's view are question-begging. The alternative views discussed have ways of accommodating the data that the author takes to count in favor of their view. The author fails completely to discuss these. The responses to objections are inadequate. In general, the discussion of alternative views is highly uncharitable and ill-informed.

Turmoil: José Luis Bermudez et al., "Philosophers should not be sanctioned over their positions on sex and gender", Inside Higher Ed, July 22, 2019, https://www.insidehighered.com/views/2019/07/22/ philosophers-should-not-be-sanctioned-their-positions-sex-and-gender-opinion; Linda Alcoff et al., "On philosophical scholarship of gender: A response to "12 leading scholars"', Blog of the APA, August 7, 2019, https://blog.apaonline.org/2019/08/07/on-philosophical-scholarship-of-gender-a-response-to12-leading-scholars/. Are women ... ?: Alex Byrne, "Are women adult human females?", Philosophical Studies 177 (2020): 3783-803. 
Since Referee 1 was rather short on specifics, naturally I wondered what, exactly, Are women ... 's grave failings were supposed to be. I am therefore genuinely grateful to Dembroff for attempting to fill in the details.

"Escaping the natural attitude about gender" (henceforth Escaping ... ) is trenchant, to put it mildly. ${ }^{2}$ Dembroff's reply convicts me of "rhetorical bullying", of using "cherry-picked quotations to undermine the legitimacy of queer communities", of deploying "uninformed and poorly constructed" arguments, and much else besides. ${ }^{3}$ Are women ...? is unmasked as a Trojan Horse, "fundamentally ... an unscholarly attempt to vindicate a political slogan that is currently being used to undermine civic rights and respect for trans persons". ${ }^{4}$

Let us start with the least inflammatory of these accusations, my poorly constructed arguments, which "are at best confused—more often, they are question-begging or false". ${ }^{5}$

\section{The Preliminary Case for AHF}

The main thesis of Are women ... ? is this:

AHF $S$ is a woman iff $S$ is an adult human female,

where the biconditional is understood to be universally quantified and necessitated. Since "categories" in Are women ... ? are taken to be modally individuated properties, AHF is equivalent to the thesis that the category woman and the category adult human female are identical. An additional thesis is that the category adult human female is "biological (and not social)", something that Dembroff also questions and which I will take up later. ${ }^{6}$

Escaping... makes unnecessarily heavy weather of establishing that my thesis "must be one about identity", as if what I said was somehow unclear. ${ }^{7}$ Dembroff incorrectly claims that I "disagree" with metaphysicians who hold that "necessary equivalence is importantly distinct from identity"; all I say is that "It will do no harm to individuate categories modally: necessarily equivalent categories are identical". 8 As Are women ... ? notes, the relevant arguments do not turn on hyperintensional differences.

Are women ... ? also makes some other clarificatory points, including:

... the evidence relevant to assessing AHF should not be sought in the "ordinary use" of 'woman' and the like: a mistaken conception (for instance) can lead people to systematically misapply words. Having said that, there is nothing wrong with appealing to linguistic evidence that clearly bears on the meaning (or intension) of 'woman', since that has immediate implications for AHF via disquotational principles. (No doubt there is some connection between ordinary use and meaning, but it is highly indirect and not well understood.) A simpler sort of evidence comprises facts about where the women are in various actual and counterfactual situations ... In what follows, appeal will be made to evidence of both sorts. ${ }^{9}$

2 Robin Dembroff, "Escaping the natural attitude about gender", Philosophical Studies 178 (2021): 983-1003.

lbid., 989, 995, 1000.

Ibid., 1001.

Ibid., 985.

Are women ...? ?, 3785

Escaping..., 986.

Ibid., 985; Are women ... ?, 3784, n. 2, emphasis added (quoted in Escaping..., 985, n. 12).

Are women ... ?, 3785, last emphasis added. 
and:

Naturally such appeals can be disputed. People vary in their abilities to correctly identify members of categories, or to correctly apply words ... It can be tempting to respond to such disagreement by losing one's nerve and retreating to the claim that one's evidence really consists in neutrally characterized facts about speakers' use of words, or (perhaps worse) facts about "intuitions"-evidence that one's opponents are less likely to challenge. That temptation should be resisted. ${ }^{10}$

The evidence I intend to adduce in favor of AHF, then, includes (a) linguistic facts that clearly bear on the meaning of 'woman' and (b) non-linguistic facts about women. That evidence does not include facts about "intuitions" or the "ordinary use" of words.

Section 2 of Are women ... ? gives six (non-demonstrative) arguments in support of AHF, three employing an (a)-type premise (e.g., that there is a robust cross-linguistic pattern of gendered words for the adult male and female forms of certain animals), and three employing a (b)-type premise (e.g., that the journalist Norah Vincent's attempt to infiltrate groups of men had no effect on her status as a woman). The point of these arguments is to reinforce Bettcher's remark that "On the face of it, the definition "female, adult, human being" really does seem right. Indeed, it seems as perfect a definition as one might have ever wanted". ${ }^{11}$ The onus is thus on AHF's opponents-hardly an implausible result. Most of the action is in Section 3, where I attempt to rebut the main arguments against AHF, due to Bettcher and Stoljar. ${ }^{12}$ The case for AHF is not complete until the end of that section.

According to Dembroff, however, I have mischaracterized Section 2 of my paper. Escaping... interprets me as offering six considerations in support of a semantic claim, that "the philosophically relevant meaning of 'woman' refers to adult human female". ${ }^{13}$ What's worse, despite my official disavowal of "ordinary usage" and "intuitions", all my arguments are said to "entirely rely on particular, everyday uses of 'woman' and 'girl'," accompanied by "linguistic intuitions". 14

First, Dembroff's claim that Are women...? assumes that "[t]here is one meaning of 'woman' relevant for philosophical inquiry" is incorrect. ${ }^{15}$ Are women...? simply engages with the many writers in the feminist tradition who at least seem to be using the word

10 Ibid., 3785, emphasis added.

11 Talia Mae Bettcher, "Trans identities and first-person authority", in "You've Changed": Sex Reassignment and Personal Identity, ed. Laurie Shrage (Oxford: Oxford University Press, 2009), 105; quoted in Are women ... ?, 3791. Bettcher herself rejects AHF, and may well think the definition is only superficially attractive.

12 Are women ...? briefly discusses other arguments in footnotes (3792, n. 15 and 16). For a deeper examination of some of these and more, including Bettcher on 'womanly' (n. 15), see Tomas Bogardus, "Evaluating arguments for the sex/gender distinction", Philosophia 48 (2020): 873-92.

13 Escaping ..., 986.

14 Ibid., 985, n. 9; 986, n. 14. It might be helpful to contrast the actual argument of Are women ... ? with Dembroff's reconstruction: here are six arguments that jointly make AHF "of considerably greater initial appeal than the JTB analysis of knowledge" (Are women ... ?, 3790); none of the leading objections work; hence AHF is true (or is at least a very plausible hypothesis) and (assumed with almost no argument) woman is a biological and not social category. This bears very little relation to the "reconstruction" (Escaping..., 984-85). That has six premises, and I only accept premise 4 ("Adult human female is a biological and not social category") and premise 3 ("On the "standard" meaning of 'woman', 'woman' refers to the category adult human female"). However, premise 3 is not a premise of the argument in Are women ... ? See Section 3 below.

15 Escaping..., 984. 
'woman' in the same standard, everyday sense, whatever that is, and who are asking questions and propounding theories using that word. I am joining their conversation, and my use of 'woman' is supposed to be interpreted in the same way as theirs. (I shall return to this issue at greater length later.) Perhaps there are other senses of 'woman' that are more "relevant for philosophical inquiry"-Are women...? takes no stand on this point.

Second, why does Dembroff think that all of my arguments rely on linguistic evidence? Take Norah Vincent's convincing attempt to live as a man. The relevant evidence is this:

... Vincent did not become a man. As it happens, she made some serious attempts to transform her body by weightlifting and eating lots of protein, but even if her preparations had included testosterone supplements, she would have remained a woman. Imagine that, due to misreading Judith Butler, Vincent became convinced (and perhaps alarmed) for a few months during her fieldwork that her performance as a man made her one. If that had happened, she would have been wrong. ${ }^{16}$

AHF, if true, straightforwardly explains this evidence, and is thereby supported by it-although, of course, not conclusively. The cumulative effect of the six considerations is intended to establish AHF as the default hypothesis.

On the face of it, the premise of the Vincent argument does not concern "everyday uses" of words. Dembroff sees that I "might protest" at this point, and replies in a footnote that the argument appeals "to what are stipulated as "correct" descriptions of persons as falling under the term 'women'". ${ }^{17}$ This is incorrect. Nothing is said about the word 'woman'. Nor, for that matter, is anything stipulated. The relevant piece of evidence is that Vincent remained a woman. ${ }^{18}$ This does have linguistic consequences, for instance that the English sentence 'Vincent remained a woman' and the German sentence 'Vincent blieb eine Frau' are both true. But the evidence itself is not about the word 'woman' at all.

Pace Dembroff, it isn't true that my allegedly non-linguistic arguments are really hidden linguistic ones. And anyway Dembroff's complaint applies equally well, or equally badly, to numerous arguments inside and outside philosophy, including the arguments in Escaping .... itself.

What about Escaping...'s charge that my linguistic arguments, at least, have premises about "ordinary usage", despite my statement to the contrary? By the "ordinary use" of a word, I meant ordinary speakers' dispositions to apply the word. (An imprecise characterization, of course, but further precision was unnecessary.) As the first indented quotation from Are women...? notes, speakers can be disposed to systematically misapply words, and so there is no straightforward route from ordinary use, conceived in this neutral fashion, to meaning. ${ }^{19}$ None of the linguistic arguments employ a premise about ordinary use in this sense. But don't dictionaries record (or attempt to record) "ordinary use"? Only in the sense that they record (or attempt to record) what words are ordinarily used to mean-this is not "ordinary use" as it figures in Are women...?

16 Are women...?, 3789.

17 Escaping ..., 986, n. 14.

18 And also would have remained one if she had taken testosterone or misread Butler.

19 For a sophisticated attempt to give a "use" theory of meaning, see Paul Horwich, Reflections on Meaning (Oxford: Oxford University Press, 2005). 
Perhaps Are women...? should have belabored these ground-clearing issues. In any event, the origin of Dembroff's misunderstanding is clear. It is my use of quotations from the New York Times, the subtitle of Vincent's book ("One Woman's Year Disguised as a Man"), and so forth:

Byrne also appeals to The New York Times, a 2010 Pourriat film, a 2003 Vincent memoir, and a carefully chosen quotation from a trans author, Julia Serano. ${ }^{20}$

However, Are women...? does not appeal to the NYT or any of these other sources. Take the NYT, which Dembroff says I appeal to "multiple times". ${ }^{21}$ (The NYT is mentioned twice.) Here is how Are women...? uses the NYT, in connection with Pourriat's film Majorité Opprimée:

As the New York Times (correctly) puts it, "the parent doing the chores is a man, and all the gender roles are reversed, creating a world in which men confront what it would be like to face the daily indignities, compromises and risks that women often face" ... This is exactly as predicted by AHF: in the fictional world of the film, the occupants of the female gender roles are adult human males. ${ }^{22}$

Escaping... appears to interpret this passage as saying: the NYT has printed and endorsed 'the parent doing the chores is a man', so this supports the view that 'man', as used by the $N Y T$, applies to an adult human male occupying a female gender role. But, as signified by the parenthetical 'correctly', the passage is actually saying something quite different, namely: (in the fictional world) the parent doing the chores is a man, which is exactly as predicted by AHF; by the way, the NYT agrees. Are women...? uses a parallel construction for the second $N Y T$ quotation. The main point of these quotations is to reassure the reader-if reassurance is needed-that my own opinions are not idiosyncratic. Notice that "what is predicted" by AHF is that the parent doing the chores is a man; AHF does not predict what may or may not appear in newspapers. The crucial piece of evidence is therefore that the parent doing the chores is a man, not that some journalist has written a sentence to that effect.

\section{Dembroff's Objections}

Having hopefully cleared all that up, where do the six arguments of Section 2 go wrong? Here are their respective premises, concisely put:

P1. The dictionary definition of 'woman' is 'adult human female' (or equivalent).

$P 2$. There are many gendered animal words which refer to adult females/males.

P3. We know that Mitochondrial Eve is a woman/We know that Y-chromosomal Adam is not a woman.

P4. When a human female is born, it is almost invariably known by inspection that the baby is female and that she is a girl.

P5. In Majorité Opprimée, the males who occupy female gender roles are men/Norah Vincent remained a woman.

P6. 'Woman' and 'female' are appropriately used as stylistic variants in certain contexts.

20 Escaping..., 989.

21 Ibid., 988.

22 Are women...?, 3789, emphasis added. 
For each one, we can ask both: Is Dembroff denying the premise? Is Dembroff denying that the premise lends support to AHF?

With respect to P1, Dembroff seems to be skeptical that the dictionary definition is evidence of anything:

... Byrne claims that "the dictionary" definition provides evidence that 'woman' means 'adult human female'. Let's set aside problems with using the dictionary to do philosophy of language. ${ }^{23}$

The main objection, though, is that "woman' may have multiple meanings". ${ }^{24}$ Waiving "problems with using the dictionary", "[e]ven dictionaries list multiple meanings for 'woman'". ${ }^{25}$ Indeed they do. This would be highly relevant if the 'adult human female' entry was not the first, or was marked 'Obs.' or something like that. But it is the first. Unless dictionaries are completely useless as guides to the meanings of words, it must be admitted that P1 provides some support for AHF. As Are women...? takes pains to point out, this is by no means decisive, but it is a consideration nonetheless. ${ }^{26,27}$

Escaping... offers no comment on P2, about the prevalence of pairs like 'goose' and 'gander'. ${ }^{28}$ On P3, about the Adam and Eve of human genetics, Escaping... says that "supporting the sufficiency direction of AHF [that being an adult human female is sufficient for being a woman] is highly uninformative", seemingly on the ground that a similar argument would support the view that being a lesbian or a wife is sufficient for being a woman. ${ }^{29}$ If there is an objection here, it is not apparent. Moreover, Escaping... ignores Y-chromosomal Adam, who is exhumed to support the necessity direction.

With respect to $\mathrm{P} 4$, the problem, according to Escaping..., is that the argument:

23 Escaping...: 988-89; footnote omitted. Also: "Byrne even suggests we will find this meaning in the pages of a dictionary" (987, emphasis added), as if this is hopelessly naïve.

24 lbid., 988.

25 Ibid., 989.

26 P1 provides support for both parts of the overall conclusion: "dictionaries ... are hard to reconcile with the idea that woman is a social category. A natural alternative is that the category is biological, and the dictionary entry 'adult human female' is at least a promising suggestion" (Are women ... ?, 3787).

27 Dembroff notes that Merriam-Websters "lists six" definitions of 'woman'. The first is "an adult female person", but Dembroff highlights one of the others: "distinctively feminine nature" (Escaping..., 989, n. 25). Examples of that sense from the Oxford English Dictionary are sentences like 'She knew that all the woman in her somewhat masculine nature had gone out, in maternal affection to her husband's nephew'. This—I would hope! —is not the relevant sense of 'woman' (see the following section). Escaping... does not mention that the remaining four subsidiary definitions are: "womankind", "a woman who is a servant", "wife/mistress/girlfriend", and "a woman who is extremely fond of or devoted to something specified", as in the sentence 'I'm a chocolate woman through and through'. 'Woman' as used in the second and last of these four clearly has its primary sense.

Going by dictionaries, the primary sense of 'woman' has remained stable for centuries. Noah Webster's American Dictionary of the English Language (1828) has "The female of the human race, grown to adult years".

Later Dembroff attaches some importance to the fact that one sense of 'girl' is (as the OED has it), "a woman of any age" (Escaping..., 990). (Another sense is "young woman".) Why this is relevant eludes me. 'Girl' in Are women ... ? has the sense it has in 'women and girls'. Dembroff also wonders why my so-called "semantic inquiry" does not extend to 'lady', 'miss', 'widow', 'tomboy', 'lesbian', etc. (990). Here I am just following the literature I engage with—which generally doesn't even use 'girl', and instead focuses rather myopically on 'woman'.

28 There is plenty to be said. For a good start, see Justin E. H. Smith, "Are cows adult bovine females?", 2019, https://www.jehsmith.com/1/2019/12/are-cows-adult-bovine-females.html.

29 Escaping ..., 986, n. 14. 
... simply stipulates that a female-assigned baby is "known" to be a girl. If this argument has more content than the claim that people use the term 'girl' to describe female-assigned babies, I couldn't find it. ${ }^{30}$

This is another of Escaping...'s peculiar uses of 'stipulation'. Claims are made, which Dembroff is free to dispute, but nothing is stipulated. ${ }^{31}$ Neither does Are women...? say anything about "female-assigned babies"; despite P4 standing in plain sight, Escaping... distorts it. And why the scare quotes around 'known'? It's hard to be sure, but it looks like Dembroff does not accept P4. Why? If support for P4 is needed, one can find it in the knowledge norm of assertion: in typical cases, there is nothing wrong with asserting that the mewling baby is a girl, or that she is female. ${ }^{32}$

With respect to P5, about swapped gender roles, Escaping... repeats the incorrect complaint that the premise is "stipulated", and alleges that the argument appeals to "intuition pumps about what counterfactual statements "ordinary" people (people who share Byrne's linguistic intuitions?) would assent to". ${ }^{33}$ This is also incorrect: there is no such premise about "ordinary people".

Finally, with respect to P6, the problem seems to be that my quotation from Serano was "carefully chosen". ${ }^{34}$ Perhaps some other quotation from Serano illustrates how she sometimes does not use 'woman' and 'female' as stylistic variants in a context where other people would. It is rather unlikely that this is true, but it is in any case irrelevant. ${ }^{35}$ The premise is that it is appropriate to so use these terms; the premise is not that Serano in fact uses 'woman' and 'female' that way. ${ }^{36}$

Are women...? predicts "[p]ointless charges of "begging the question"”' (probably an effect of Referee 1's report). ${ }^{37}$ Undeterred, Dembroff insists that some-if not all—of my arguments do indeed beg the question. ${ }^{38}$ Given the explicit prediction, one would have hoped that Escaping... would carefully spell out why. Unfortunately, it does not. I can only presume that the following observation applies here:

Sometimes philosophers lapse into a use of 'begging the question' that sheds no lights whatsoever on a debate, teetering on the most pointless use whereby one automatically classifies an argument against a position as question begging when its premises support an unwelcome conclusion. ${ }^{39}$

30 Ibid., 986, n. 14.

31 More carefully, Are women ... ? does have one hypothetical case which can fairly be said to be "stipulated" (3793). But this is the entirely innocuous sense in which Gettier's hypothetical cases are stipulated.

32 See Timothy Williamson, Knowledge and Its Limits (Oxford: Oxford University Press, 2000), chap. 7.

33 Escaping ..., 986, n. 14.

34 Ibid., 989.

35 See Julia Serano, "Transgender people and "biological sex" myths", Medium, July 17, 2017, https: //medium.com/@juliaserano/transgender-people-and-biological-sex-myths-c2a9bcdb4f4a.

36 So when Dembroff remarks in a footnote that "one of Byrne's six arguments in favor of AHF ... is that 'woman' and 'female' are used interchangeably" (Escaping..., 990, n. 31), this is incorrect.

37 Are women ... ?, 3785.

38 Escaping ..., 985.

39 Herman Cappelen and John Hawthorne, "Reply to Lasersohn, MacFarlane, and Richard", Philosophical Studies 156 (2011): 449-66, 464. 
Escaping...'s objections to the six considerations dissolve on closer examination; if they are the best on offer, the preliminary case for AHF looks stronger than ever.

Escaping... contains a couple of other objections which it will be helpful to examine at this point. The objections are not directed to any specific argument, but rather to Are women...?'s conclusion. They focus on AHF's 'adult' part, and the 'juvenile' part of its counterpart for girls:

JHF $S$ is a girl iff $S$ is a juvenile human female. ${ }^{40}$

The first objection is that "the most charitable version" of my view draws the line between juvenile and adult at "a point of physical maturity associated with being impregnatable", and this is too early: "Woman' is rarely used to describe pubescent adolescents, such as fifteen- and sixteen-year-olds". ${ }^{41}$ ('Ugly' is rarely used to describe the ugly; the objection should rather be: 'Woman' does not apply to pubescent adolescents.) Dembroff is raising some pertinent questions. When does juvenility shade off into adulthood? (Of course, both 'juvenile' and 'adult' are vague, as is 'woman'.) And does 'adult' capture the developmental stage at which one becomes a woman?

Regarding the first question, human females have fully matured into the adult form at the end of puberty, which is around 15 or 16 . AHF is thus false if these people are not women. But it is hardly clear that they are not: 'They are young women' seems unexceptionable. However, for the sake of the argument, let us grant that these young adult females are not women; the answer to the second question is therefore 'no'. To repair AHF, 'adult' needs to be restricted to remove those in the very early stages of adulthood. That would not affect the basic claims of Are women...? in any way. The paper anticipates worries of exactly this kind: "one should be wary of claiming that AHF is more than a very good approximation". ${ }^{42}$

It may be that any reductive thesis along the lines of AHF remains no more than close enough. Non-reductionism's slogan is Women First! ${ }^{43}$ Antony has recently defended Women Firstism, with her version not conceding that woman entails female. ${ }^{44}$ If reductionism fails, that need not spoil the project of Are women ... ?, because a good case can be made that woman is a non-social category without appealing to a reductive analysis. (On the relative importance of "non-social" and "biological", see Section 7 below.)

Dembroff's second objection is not against AHF, but instead is directed towards the second part of my conclusion, that woman is not a social category. The problem is said to be that "[e]ven with respect to ordinary language, such as the proliferation of terms like

40 Are women...?, 3788.

41 Escaping..., 990.

42 Are women...?, 3785. Other potential counterexamples include precocious puberty and older females with absent puberty. Questions also arise about 'human' in the statement of AHF. Similar terms for female animals sometimes cut across species boundaries: a female hawk is a hen, but hawks come in many different species. Modern humans interbred with Neanderthals, usually regarded as a different species. Were these matings between (for instance) men who were humans and women who were Neanderthals, or merely between men and adult female Neanderthals? The answer is not clear. (There is nothing odd about 'Neanderthal women', but that may be like 'Twin-Earth water'; for an example of the single word 'women' applied to adult female Neanderthals, see Rebecca Wragg Sykes, "Sheanderthal", Aeon, January 12, 2021, https://aeon.co/essays/what-do-we-know-about-the-lives-of-neanderthal-women.)

43 Are women ... ?, 3790

44 Louise Antony, "Feminism without metaphysics or a deflationary account of gender", Erkenntnis 85 (2020): 529-49. See also Mari Mikkola, "Elizabeth Spelman, gender realism, and women", Hypatia 21 (2006): 77-96, 90-3; Toril Moi, "Thinking through examples: What ordinary language philosophy can do for feminist theory", New Literary History 46 (2015): 191-216, 202. 
'adulting', it seems clear that "adult" is a social category". ${ }^{45}$ And if 'adult' in the statement of AHF means something like 'legally/socially an adult', then, if AHF is true, woman is a social category. But I trust it is clear that 'adult' in the statement of AHF is supposed to be interpreted as in 'adult chimpanzee'; that is also the natural interpretation of 'adult' in the dictionary entry for 'woman'. Other senses of 'adult' are irrelevant.

\section{Multiple Meanings}

Since Escaping... devotes so much space to emphasizing that my "philosophically naive framing" short-changes polysemous and contextualist accounts of 'woman', the issue needs exploring more thoroughly. ${ }^{46}$

As Dembroff notes, Are women...? does mention both polysemy/ambiguity and contextualism. I criticize Saul's contextualist proposal (which she does not actually endorse) in a footnote. Dembroff hyperbolically asserts that my criticism of Saul "displays a startlingly uncharitable reading", but set that aside. ${ }^{47}$ In another footnote, I briefly argue against Stone's suggestion that 'woman' is ambiguous/polysemous between an "adult human female" reading and a social "gender" reading. ${ }^{48}$ The same argument counts against the view that the polysemy in 'woman' is even more extensive, although Escaping... does not notice it.

In yet another footnote, I examine Bettcher's "multiple-meaning position", on which 'woman', in addition to its standard or "dominant" meaning, also has a "resistant" meaning in the idiolects of some "trans subcultures". According to Escaping..., my response:

... is to dismiss this as irrelevant to philosophical inquiry. Even if there are multiple meanings of gender terms, Byrne asserts, the meaning "clearly in play in the relevant literature" is the "dominant" meaning. By "dominant" meaning, it is safe to presume that Byrne means a meaning that best accords with their own linguistic intuitions-as well as dominant power structures. ${ }^{49}$

This is incorrect. First, I do not dismiss Bettcher's "resistant" interpretation as irrelevant to philosophical inquiry. (I touched on this point earlier, in Section 1.) In fact, if she is right, I would think it quite interesting to examine the resistant interpretation further. (I do give reasons for doubting that there is such an interpretation, however.) Second, the 'dominant' terminology is Bettcher's, not mine, and it is "safe to presume" only that I mean whatever she does. The resistant meaning of 'woman' is simply its meaning "as deployed

45 Escaping..., 996.

46 Ibid., 987.

47 Ibid., 987, n. 18, emphasis added. That footnote inaccurately paraphrases my "cursory arguments" against Saul. It also cites Jenkins and Bettcher as potential replies to one of my objections, about circularity; for critical discussion see Tomas Bogardus, "Some internal problems with revisionary gender concepts", Philosophia 48 (2020): 55-75.

One indication that AHF has been prematurely rejected is the proliferation of baroque and wildly diverse accounts of woman (or 'woman') and other gender categories (or words), each with its own set of serious problems. To take a recent example, Heather Logue ("Gender fictionalism", Ergo (Forthcoming)) ingeniously defends "gender fictionalism", according to which our talk of women, boys, and so on, is an unwitting pretense. In reality, there are no women or boys-"genders are fictional properties". That may be no less plausible than other post-AHF accounts.

48 Are women...?, 3790-1, n. 12.

49 Escaping ..., 987-88, footnote omitted. See also: ““Dominant” uses of gender terms—by which I take Byrne to mean ... ," 988. 
in trans subcultures"; the dominant meaning is then the word's meaning as deployed in mainstream culture. ${ }^{50}$ The Escaping... passage continues:

But, in that case, Byrne's claim that [the dominant meaning is] at play in the "relevant literature" is puzzling. I cannot help but wonder why work by the central figures of the philosophical literature, not to mention work by anthropologists, sociologists, and linguists, is "irrelevant", and where this elusive "relevant literature" is to be found. ${ }^{51}$

The Bettcher footnote is appended to a paragraph which cites a considerable number of feminist writers from the 1970 s and later. The preceding paragraph mentions three contemporary feminist philosophers, Jenkins, Stoljar and Saul. The word 'woman' frequently figures in the writings of these many feminists. They evidently intend to use 'woman' to discuss a common subject matter, and freely quote one another using the word. They appear to have many "simple disagreements" about women: there is a single proposition expressed using the word 'woman', which one party believes and the other does not. ${ }^{52}$

Take, for instance, Spelman's canonical Inessential Woman. ${ }^{53}$ Spelman quotes many authors on the topic of women, and critically examines what they say. Some are not feminist philosophers, like Aristotle and Kant. Some are not philosophers, like the sociologist Nancy Chodorow and the travel writer Jan Morris. Spelman even discusses a New York Times article that uses the word 'woman'. ${ }^{54}$ As Mikkola puts it, Spelman argues against "the view that woman have some feature (definitive of 'womanness') in common and this feature is what makes them women"; according to Mikkola, Spelman's "case against it is inadequate". ${ }^{55}$ Mikkola and Spelman appear to have a simple disagreement over the negation of the thesis named by the penultimate quotation: Spelman believes it, and Mikkola does not. They are not talking past each other, or using 'woman' in some specialized technical sense. ${ }^{56}$ This is one example of the "relevant literature" that Dembroff finds "elusive".

Dembroff incorrectly claims that my argument "proceeds with the unargued-for assumption that there is one, unvarying answer to the question What does the word 'woman' mean?". ${ }^{57}$ Rather, a working assumption of Are women...? is that 'woman' has a standard interpretation in the literature I am discussing, and that it is an interpretation that the word has in many everyday contexts. This is completely compatible with polysemy of the kind recorded in the Oxford English Dictionary, and even with a mild form of contextualism. Protesting that this assumption is unwarranted would be to indict swathes of classic feminist philosophy.

50 Talia Mae Bettcher, "Trans women and the meaning of "woman"”, in Philosophy of Sex: Contemporary Readings, Sixth Edition, ed. Nicholas Power, Raja Halwani and Alan Soble (Lanham, MA: Rowan Littlefield, 2013), 243.

51 Escaping ..., 988.

52 See Cappelen and Hawthorne, "Reply ... ", 452. 'Not believe' should be read as including suspension of belief, not just disbelief. For present purposes, a "simple disagreement" is really a "simple non-agreement".

53 Elizabeth V. Spelman, Inessential Woman: problems of exclusion in feminist thought (Boston: Beacon Press, 1988).

54 Spelman is sensitive to the possibility of ambiguity, and argues that Plato "uses "woman" ambiguously" (ibid., 32).

55 Mikkola, "Elizabeth Spelman, gender realism, and women", 77, 79.

56 Not that this never happens: see Are women ... ?, 3791, n. 13.

57 Escaping..., 987. 
Still, Dembroff does seem to want to defend the radical polysemy view, that 'woman' has multiple meanings in everyday contexts, outside the gender studies seminar room, with no single meaning being clearly "dominant". ${ }^{58}$ In support of this, Escaping... quotes a passage from Barnes, in which she speculates that "teenagers probably mean something quite a bit different" by their "gender terms" than do their grandparents and even other teenagers. ${ }^{59}$ Teenagers have their own argot, of course. If your teen is inviting someone over for "Netflix and chill", that is not as innocent as it sounds. And "gender terms", for Barnes, include not just 'woman' and 'man', but also the voguish 'pangender', 'genderfluid', 'genderqueer', 'agender' and so on. ${ }^{60}$ Doubtless, a number of especially benighted grandparents don't even understand these words. But what about 'woman'? If some teenage idiolects attach a deviant meaning to the word, this shows nothing about 'woman' as used in everyday adult conversation and writing. Also, it is not remotely credible that teenagers do not understand the word 'woman' as used by their parents and schoolteachers, and as it appears in Sojourner Truth's speech "Ain't I a Woman?". They have that word with its usual meaning in their lexicon too, and can use it when the grown-ups are around.

The only other piece of evidence that Dembroff adduces for the radical polysemy view is that there are "endless examples" from "law, print media, social media, policy documents, and education, where 'woman' is used with meanings other than adult human female". ${ }^{61}$ (On what these alternative meanings are, Escaping ... has little to say.) From these endless examples, Dembroff selects a couple of sentences from newspapers about transgender women. ${ }^{62}$ No explanation is given of why "woman" in these sentences does not denote adult human female. Perhaps Dembroff thinks that if it does, both sentences are false because transgender women are not female, and charity dictates a true interpretation. This is entirely unconvincing: people can be wrong about what women are, or disagree about what women are, just as they can be wrong or disagree about almost anything. Certainly some readers would say that these sentences are not literally true. And when people give every sign of disagreeing, often the most charitable interpretation is that they are, not that they are talking past each other. (Given Escaping...'s later discussion of sex, this hypothesis about Dembroff's reasons may not be right: see Section 7 below.)

Linguists have developed a variety of tests for polysemy, none of which Dembroff uses. ${ }^{63}$ And, on the face of it, there is no indication that the sense of 'woman' in Dembroff's selected sentences is different from its sense on other pages of the newspaper, whatever that sense might be.

Elizabeth Barnes, "Gender and gender terms", Noûs 54 (2020): 704-30, 712; quoted in Escaping..., 988.

Ibid., 710, 723.

61 Escaping..., 989.

62 Ibid., 988, n. 23. "Author David Thomas still lives as a man, but has begun the male-to-female gender transition that will eventually result in becoming a woman" (discussed below); "At least 22 transgender people have been fatally shot or killed in 2019... Nearly all of them were black women" (Lola Fadulu, "Trump's rollback of transgender rights extends through entire government", New York Times, December 6, 2019, https://www.nytimes.com/2019/12/06/us/politics/trump-transgender-rights.html).

63 See, e.g., Andrei Moldovan, "Descriptions and tests for polysemy", Axiomathes (2019): 1-21, https:// doi.org/10.1007/s10516-019-09445-y. Jake Quilty-Dunn suggests (with respect to the present dispute) that 'female' may be (relevantly) polysemous, although he does not argue for it ("Polysemy and thought: toward a generative theory of concepts", Mind and Language (2020): 1-28, 22, https://doi.org/10.1111/ mila.12328). See also Are women ... ?, 3798, n. 29. 
Take Dembroff's first example, which is from an article in a series in the UK newspaper The Daily Telegraph, chronicling the journalist David Thomas's transition to Diana. The quotation is from the dek to the article, and we may safely assume that Thomas and the dek writer are using 'woman' with the same sense. At one point in the series, Thomas writes:

Women, in particular, are being told that childbirth and menstruation, the most quintessentially, definitively female experiences are no longer reserved for women. In fact, it is offensive to say so. They are also expected to welcome anyone who says they are female into female-only environments.

These demands are not being made by all transgender people. Many of us-I would guess the majority-are appalled by the aggression and unreasonableness of people who claim to speak in our name. And we are horrified by the totally counter-productive, but entirely predictable outcomes of their stridency. ${ }^{64}$

The reader can only presume that Thomas is using 'women' with whatever meaning it has in an ordinary context in which transgender issues are not salient. ${ }^{65}$ Similarly, when Thomas writes in the first article, "do I actually think that I am a woman? No, I don't. I may become one in time, but not yet", and later, when a fellow journalist writes in a coda to the series, "It has to be said that the woman I encounter today is a world away from the man I knew during a period in the 1990s when, as journalists, we would frequently find ourselves writing on opposite sides of the gender divide". 66 Unless the Telegraph's series is fundamentally unintelligible, the word 'woman' has a single and common meaning throughout.

\section{A Polysemy Puzzle}

Escaping...'s apparent endorsement of the radical polysemy view leads to a puzzle. If 'woman' has a variety of different meanings in newspapers and the like, shouldn't one of these meanings correspond to the category adult human female? Why wouldn't it? And if that is one meaning of 'woman', then the palm should be awarded to Stone, who said years ago that "in everyday language 'woman' ... is ambiguous between sex and gender"; that is, 'woman' is ambiguous between an adult human female interpretation and a (presumably related) social "gender" interpretation. ${ }^{67}$ On the radical polysemy

64 Diana Thomas, "From gender-neutral bathrooms to women's prisons, it's time trans people carried ID cards", Daily Telegraph, October 23, 2019, https://www.telegraph.co.uk/women/life/gender-neutralbathrooms-womens-prisons-time-trans-people-carried/.

65 In the above quotation on the Telegraph website, 'no longer reserved for women' links to an article by the journalist and feminist activist Julie Bindel ("By caving in to trans activists, Always have eliminated women", Daily Telegraph, October 21, 2019, https://www.telegraph.co.uk/women/life/cavingtrans-activists-always-have-eliminated-women/), which uses the word 'women' (and which is also in the "Women" section of the Telegraph). Clearly Bindel would not take Dembroff's two sentences (in context) to be literally true.

66 Diana Thomas, “I'm not going to turn into one of those angry, shouty transsexuals, am I?", Daily Telegraph, March 30, 2019, https://www.telegraph.co.uk/family/life/someone-spouts-ignorant-nonsenselatest-transgender-issue-hurts/; Jane Gordon, "'Call me Diana': Our columnist David Thomas reveals her new life and look", Daily Telegraph, March 14, 2020, https://www.telegraph.co.uk/health-fitness/body/ call-diana-columnist-david-thomas-reveals-new-life-look/.

67 Alison Stone, An Introduction to Feminist Philosophy (Cambridge: Polity, 2007), 141; see Are women...?, 3790 , n. 12. 
view, Stone's only mistake was to think that there were two "dominant" or mainstream meanings-in fact, there are many more. Further, if this is right, then Are women...? is not completely wrong either. It manages to be closer to the truth than Bettcher's "Trans women and the meaning of "woman"' and Stoljar's "Essence, identity, and the concept of woman", which hold that there is no dominant meaning of "woman" on which it denotes the category adult human female.

There is some indication that Dembroff agrees that on one dominant meaning of 'woman', it does denote adult human female. There is the quotation in the previous section, " . . . is used with meanings other than adult human female", which suggests that 'woman' is sometimes used with that meaning. And, according to Escaping..., there is "evidence that, in certain contexts and communities, these terms [e.g., 'woman'] take on meanings that entail or include physiological features". ${ }^{68}$ (No clear evidence is cited, however. ${ }^{69}$ ) Finally, the extreme version of the principle of charity that apparently leads Dembroff to conclude that there are "endless" examples where "woman' is used with meanings other than adult human female" could be used equally effectively to argue that there are endless examples where 'woman' does mean that.

But it is hard to see how this interpretation could be correct. If 'woman' has a "dominant" interpretation on which it denotes adult human female, then of course Escaping... should have simply said so and cited Stone, which it does not. Moreover, this would imply that my arguments are nowhere near as bad as Escaping... makes them out to be. For instance, in the specific ordinary sense of 'woman' that I must have had in mind, premise P5 of the "swapped gender roles" argument is true. ${ }^{70}$ The problem would not then be with the argument, but with my unthinking assumption that, in the context of debating philosophers like Bettcher and Stoljar, all three of us are using 'woman' with the same ordinary meaning. Finally, on this interpretation Are women...?'s cautionary advice about activist sloganeering would still apply. ${ }^{71}$ We will have to leave this puzzle unresolved..$^{72}$

68 Escaping ..., 988.

69 The sentence preceding the one quoted is supposed to provide evidence, but it is obscure what Dembroff has in mind. Barnes does better, giving a concrete example of such "physiological features", when she imagines being in "a context where everyone is using the term 'man' in a way that only applies to people born with a penis and testicles" (Barnes, "Gender and gender terms", 712). However, it is doubtful that there are any such contexts. If I say 'All men are born with a penis and testicles', and someone mentions penile agenesis (where a male baby is born without a penis), the right response is never to double down and insist that, nevertheless, my original statement was correct.

70 A sentence expressing a premise may contain ambiguous words. The intended premise will correspond to one disambiguation. Note that this does not mean that the premise is covertly linguistic or semantic.

71 See Are women ... ?, 3800.

72 Dembroff ("Why be nonbinary?", Aeon, October 30, 2018, https://aeon.co/essays/nonbinary-identity-isa-radical-stance-against-gender-segregation) offers an argument against the "identity view of gender", that "gender is just reproductive features and nothing more". Whatever the identity view is, precisely, if Dembroff's argument succeeds, it also shows that AHF is false, with 'adult' interpreted non-socially, as in 'adult chimpanzee'. (For an explanation of why the argument does not succeed, see Bogardus, "Evaluating arguments for the sex/gender distinction", 884-85.) So perhaps Dembroff's view is that 'woman' often does denote adult human female, but only with a social interpretation of 'adult'. However, even that would partially vindicate Are women ... ? 


\section{From Semantics to Metaphysics}

As discussed, Dembroff incorrectly characterizes the overall argument of Are women...?'s Section 2 as proceeding from semantic premises to a metaphysical conclusion. In Escaping...'s mistaken reconstruction, Section 2 of Are women...? employs a crucial premise ("premise 6") to bridge the gap between semantics and metaphysics, namely "that the "philosophically relevant" meaning of the term 'woman' is a reliable guide to the metaphysics of the category woman". ${ }^{73}$ Section 3 of Escaping... is dedicated to undermining premise 6 .

Recall from Section 2 that three of the six considerations in favor of AHF only appeal to non-linguistic premises. Accordingly, they need no bridge between semantics and metaphysics. But the remaining three considerations do support AHF by directly supporting the semantic claim that 'woman' denotes adult human female. So if Escaping... shows that premise 6 is false, that might seem to threaten at least some of my arguments.

On Dembroff's telling, I have failed "to even acknowledge, much less address" an argument from Barnes that "the semantics of natural language gender terms pull apart from the metaphysics of gender". ${ }^{74}$ Even if we grant that 'woman' denotes adult human female, "the problem remains: one cannot read off the metaphysics of gender off "the meaning" of natural language terms" ${ }^{75}$

However, Barnes's argument threatens nothing in Are women...? (which does not use the phrase 'metaphysics of gender'). Indeed, one need only read the relevant paragraphs in Escaping... to see that Barnes's argument is irrelevant. Is Barnes denying elementary disquotational claims like 'If ' $S$ is a woman' is true, then $S$ is a woman'? No. But nothing more is involved in the step from "semantics" to "metaphysics". This is how Are women...? puts the step in the "dictionary" argument:

Granted that the dictionary definition gives the meaning of 'woman', the intension of 'woman' at a world $w$ is the set of adult human females in $w$, and AHF follows immediately. ${ }^{76}$

Here is another way of putting the point. Escaping... quotes Barnes approvingly, as urging that the "metaphysics of gender" requires understanding the "bedrock social structure" that gives rise to the "complicated, multi-faceted social experience of gender". ${ }^{77}$ It is certainly implausible that the semantics of 'woman' is going to be of much help with the metaphysics of gender in this Barnesian sense. But Are women...? does not pretend otherwise.

Escaping... continues with "another, largely undiscussed reason to think that natural language terms are a poor guide to the metaphysics of gender". ${ }^{78}$ Given the point just

73 Escaping..., 990-91.

Ibid., 991, n. 34; 991.

Ibid., 991.

76 Are women ... ?, 3786. Spelling the step out a little more, leaving off the universal quantifier and ignoring tense for simplicity: ' $S$ is a woman iff $S$ is an adult human female' is true at $w$ iff the referent of ' $S$ ' in $w$ is (i) a member of both the intension of 'woman' and the intension of 'adult human female' in $w$, or (ii) is not a member of either. Since the intension of 'woman' = the intension of 'adult human female', ' $S$ is a woman iff $S$ is an adult human female' is true at $w$. But this holds for all worlds $w$. Therefore, ' $S$ is a woman iff $S$ is an adult human female' is true at every world; hence 'Necessarily, $S$ is a woman iff $S$ is an adult human female' is true. The step from "semantics to metaphysics" takes us to: necessarily, $S$ is a woman iff $S$ is an adult human female. That is, AHF is true.

77 Escaping ... , 991; see Barnes, "Gender and gender terms", 717.

78 Escaping ..., 992. 
made, this does not look promising as an objection. But an argument against AHF is in the vicinity, so this cannot be passed over.

According to Dembroff, "in many contexts" 'woman and 'man' "operate as "floating signifiers", which "lack stable extensions and are not primarily descriptive". 79 "Floating signifier' is a term from semiotics, and originated with the anthropologist Claude Lévi-Strauss: "somewhat like algebraic symbols [floating signifiers] occur to represent an indeterminate value of signification, in itself devoid of meaning and thus susceptible of receiving any meaning at all". ${ }^{80}$ "Such signifiers mean different things to different people: they may signify many or even any signifieds; they may mean whatever their interpreters want them to mean". ${ }^{81}$

If AHF is true, then 'woman' and 'lioness' are both semantically very similar. On the reasonable assumption that 'lioness' is a semantically orthodox common noun, it is quite unlike any floating signifier. Therefore, if 'woman' is a floating signifier tout court, with no senses akin to 'lioness', then AHF is not true. (Or, better: there is no such proposition as AHF to begin with.)

Granted that languages do contain floating signifiers, is it plausible that "woman" is one of them? Lévi-Strauss apparently thought not. One of his examples is "when American slang says that a woman has got 'oomph"'-'oomph' is the floating signifier, not 'woman'. ${ }^{22}$ Much better candidates for floating signifiers are new coinages like 'neutrois', "a catch-all 'gender neutral' label that can mean different things to different people, such as agender, neither/nor, genderless and so on". ${ }^{83}$

What's more, the claim that 'woman' is a floating signifier tout court is incompatible with radical polysemy: polysemy is just quotidian meaning multiplied, whereas a floating signifier has no such meaning. It is fairly clear that Dembroff is claiming only that 'woman' is used as a floating signifier, "capable of taking on whatever descriptive content users wish to impose", in some contexts, not all. ${ }^{84}$ These contexts are, roughly, ones where "social or political ends" are important. ${ }^{85}$ Provided that these contexts are not operative when premises P1 to P6 are considered (Section 2 above), the preliminary case for AHF is not in danger. Incidentally, Are women...? does caution that politically charged contexts should be avoided. ${ }^{86}$

What is the evidence that 'woman' and 'man', at least on occasion, "operate as floating signifiers"? Escaping... lacks the "space to fully argue for this claim", but Dembroff does give one reason. ${ }^{87}$ Two people, perhaps a "conservative" and a "liberal", can agree on the "underlying physical, psychological, and social facts, and still continue to make ... opposing claims"-one says ' $S$ is a woman', while the other says 'No, $S$ is a man'. "This suggests" that 'woman' and 'man' are "doing normative, political work more so than descriptive work"; the conservative and the liberal are not arguing, inter alia, "about the

79 Ibid., 994.

80 Claude Lévi-Strauss, Introduction to the Work of Marcel Mauss, trans. Felicity Baker (London: Routledge Kegan Paul, 1987), 55.

81 Daniel Chandler, Semiotics: the basics (London: Routledge, 2017), 90.

82 Lévi-Strauss, Introduction, 55.

83 Gary W. Wood, The Psychology of Gender (London: Routledge, 2018), 24; see also Rebecca Reilly-Cooper, "Gender is not a spectrum", Aeon, June 28, 2016, https://aeon.co/essays/the-idea-thatgender-is-a-spectrum-is-a-new-gender-prison.

84 Escaping..., 992.

85 Ibid., 992.

86 See Are women ... ?, 3798.

87 Escaping ..., 992. 
way the world is". ${ }^{88}$ Dembroff's argument deserves much more discussion than it is going to receive here, but its form is suspicious. Consider Burge's Arthritis Man, an English speaker who knows he suffers from arthritis, that "certain sorts of aches are characteristic of arthritis" and so on; he can use the word 'arthritis' to express this knowledge. "In addition ... he thinks falsely that he has developed arthritis in his thigh". ${ }^{99}$ (This belief is false because arthritis is an inflammation of the joints.) Arthritis Man could agree with an interlocutor on the "underlying" physical and psychological facts, and yet the pair could have a simple disagreement, using the word 'arthritis' with its ordinary meaning, about whether Arthritis Man has arthritis in his thigh.

This part of Escaping... ends with an objection that repeats the incorrect claim about Are women...?'s methodology: I do not "consider the possibility that one can theorize about the metaphysics of gender using methodologies other than the analysis of natural language use". ${ }^{90}$ Oddly, Escaping... immediately goes on to note that I do mention Haslanger's ameliorative project, while managing to incorrectly claim that I misrepresent it. ${ }^{91}$ Escaping... also ignores the pessimistic remarks about the prospects for ameliorative projects at the end of Are women...? Setting these errors and omissions aside, this is not an objection against the argument of the paper, but at best the complaint that there are other more interesting projects, which Are women...? does not deny.

\section{Rebutting Arguments against AHF}

Establishing that AHF is the default hypothesis is not much of an achievement. (I suppose I can give myself a small pat on the back for apparently being the first philosopher in 2500 years to do this, though.) If Are women...? contains anything of value, it is the rebuttal of the arguments against AHF, in Section 3. After all, if AHF remains a live possibility, it would be a bad idea to lump 'woman' together with 'genderqueer' and 'pangender' as "gender terms", as if they formed a unified class. The latter two words presumably pick out social categories of some kind, and certainly not biological ones. Current methodology in the metaphysics of gender is seriously misguided unless AHF can be taken off the table.

What, then, are Escaping...'s objections to Section 3? Strikingly, there do not appear to be any. ${ }^{92}$ Perhaps Dembroff does not want to defend Bettcher's and Stoljar's arguments against AHF, but instead thinks that some other argument-radical polysemy, floating signifiers?-will do the job. Or perhaps Dembroff thinks AHF is true, albeit only in one relatively uninteresting sense of 'woman'. We will have to leave this puzzle unresolved too.

88 Ibid., 993, 992.

89 Tyler Burge, "Individualism and the mental", Midwest Studies in Philosophy 4 (1979), 73-122, 77.

90 Escaping..., 994.

91 According to Dembroff, I present the ameliorative project as "largely disinterested in describing the world"; a glance at the relevant paragraph (Are women ... ?, 3786) shows that this is incorrect. I even quote Haslanger saying that the goal is partly one of understanding-there can be no understanding without accurate description.

92 This may be a bit unfair. Dembroff does say in a footnote that my response to Bettcher's gender role reversal case is simply to "stipulate" that l'm right (Escaping..., 989, n. 28), which seems intended as an objection. In any event, the claim of stipulation is incorrect. 


\section{Social and Biological Categories}

The conclusion of Are women...? is not just that AHF is true; it is that "woman is a biological (and not social) category". ${ }^{93}$ The paper simply asserts without argument that adult human female, "like the categories vertebrate, mammal" is a biological category. ${ }^{94}$ The definition of 'social category' is borrowed from Haslanger; as Dembroff puts it, a social category has "membership conditions that are at least partly constituted by social features". ${ }^{95}$ Putting it more plainly, in order to belong to the categories Yale University professor, celebrity, or godparent, a person needs to be embedded in a society of some sort; these are accordingly social categories. ${ }^{96}$

Are women...? also gives no direct argument for the claim that adult human female is not social. ${ }^{97}$ A footnote in Are women...? says that while some have argued "that categories like female are social categories ... [t] his position is assumed false here", with a citation to an article of mine written for a popular audience. ${ }^{98}$

Escaping... finds all this immensely problematic, a regrettable result of my ignorance or misunderstanding of "relevant work in social ontology, the history of sexology, gender theory, and medical and cultural anthropology" ${ }^{99}$ After exhibiting my purported confusions, Dembroff sums up:

(A) Byrne's stipulated distinction between the "biological" and the "social" fails to show that they are exclusive, $(B)$ fails to undermine the traditional sex/gender distinction, and $(C)$ fails to show that sex categories are not, in the relevant and interesting sense, social categories. ${ }^{100}$

Escaping... spends pages agonizing over what I could possibly have meant by 'social' and 'biological'. Let me try to explain why this was unnecessary. Are women...? begins by noting that the orthodox view in the philosophical literature on gender "is that the category

ing..., 995. given in Are women ... ? and a characterization like Dembroff's, although there is no need to go into it. Are women ... ? obliquely alluded to this $(3784$, n. 2) with a reference to Sally Haslanger, Resisting Reality: social construction and social critique (Oxford: Oxford University Press, 2012), 131 (the modal version) and 87 (a more Dembroffian characterization).

97 However, an argument is given that "woman' does not pick out a social category" (Are women ... ?, 3787).

3785, n. 7 Citation: Alex Byrne, "Is sex socially constructed?", Arc Digital, November 30, 2018 , https://medium.com/arc-digital/is-sex-socially-constructed-81cf3ef79f07. Dembroff agrees that "on the very narrow view of a "social" category that Byrne uses, it is true that sex categories are not social" (Escaping..., 997). But the claim of "gender scholars ... was never and is not the claim that the membership conditions of sex categories include constitutively societal features" (997, first emphasis added). If so, then the four examples I give in $\mathrm{n} .7$ (Are women ... ?, 3785) are all wrong. Admittedly, the first three of the four are sometimes hard to interpret, but the fourth is perfectly clear: "Being of a certain sex" "is not a biological property", it "is an institutional property, in fact a legal one ... a conferred legal status" (Ásta, Categories We Live By (Oxford: Oxford University Press, 2018), 70-72).

In a footnote Dembroff wonders how I can say that "if female is a social category" (Are women ... ?, 3785$, n. 7$)$ then "[my] thesis is easier to defend", given that "[Byrne's] thesis is, in their own words, the thesis that "woman is a biological (and not social) category"' (Escaping..., 997, n. 59). The answer is in the full quotation from Are women ... ? (emphasis changed): "if female is a social category then AHF is easier to defend".

99 Escaping..., 995.

100 Ibid., 1000, labels added. 
woman is a social category, like the categories wife, firefighter, and shoplifter". ${ }^{101}$ As Barnes says, theorists of categories like woman can be divided:

... into two main camps: those who say that your gender is determined primarily by how other people react to you, and those who say that your gender is determined primarily by your own internal sense of yourself. Let's call the former externalists (since they think your gender is primarily determined by things external to you) about gender and the latter internalists about gender (since they think your gender is determined primarily by things internal to you). ${ }^{102}$

Gender externalists hold that woman is a social category in the loose and intuitive sense illustrated by the examples just before this quotation. The situation might seem different with internalists, because society is an external matter. But internalism requires society just as much as externalism. The pertinent "internal sense of yourself", or your "gender identity", involves:

... your internally felt sense of your relationship to the gender norms and categories that are common within our society. ${ }^{103}$

The category adult human female is clearly not social in the loose and intuitive sense in which theorists of gender hold that woman is a social category. Any way of making this loose and intuitive sense more precise will yield the same result, which is why Are women...? did not bother trying. Adult human females are usually found in societies, but they need not be; neither need they have the right sort of "internal sense" of themselves, or indeed any sense of themselves at all. ${ }^{104}$

Hence, if AHF is true, woman is not a social category, and orthodoxy is wrong. What sort of category is it, then? It's helpful, although not mandatory, to say something at this point. And since biologists take a special interest in sex across the animal and vegetable kingdoms, the juvenile and adult forms of organisms, and species, the obvious term is 'biological'. As Stoljar puts it:

There is only one plausible biological type that is a candidate for the species of woman: the type "[adult] female human being." 105

No general characterization of a biological category is necessary. 'Biological' could even be dropped in favor of 'non-social' and Are women...? would be in all essentials unchanged. Dembroff's (A)-complaint, that I have failed to show that the biological and the social are "exclusive", is therefore misdirected. All that matters is that adult human female is non-social in the relevant sense, no matter how 'social' is precisified.

Before getting on to $(B)$, I should correct a mistake that occurs in the course of Dembroff's discussion of $(A)$, namely that I "insist":

101 Are women ... ? 3783-4.

102 Elizabeth Barnes, "The metaphysics of gender", in The Norton Introduction to Philosophy, ed. Gideon Rosen et al. (New York: Norton, 2018), 585, emphasis added.

103 Ibid., 587-88.

104 This is another small piece of evidence in AHF's favor-women can lack a mental life entirely, due to traumatic brain injury. Cf. Barnes on Haslanger's example of "cognitively disabled women" ("Gender and gender terms", 589; "The metaphysics of gender", 710-11).

105 Natalie Stoljar, "Essence, identity, and the concept of woman", Philosophical Topics 23 (1995): 261-93, 267, emphasis added; quoted in Are women...? 3791. 
... that persons who lack uteruses and ovaries, even if they otherwise appear as "normal" females, are not adult human females. ${ }^{106}$

So supposedly on my view, one way to become a non-woman is to have a hysterectomy and an oophorectomy, which doesn't sound right! Possibly Dembroff has misunderstood the "Complete Asexual Syndrome" example. ${ }^{107}$ The necessary corrective is right there in Are women...?: "Women can lack "female reproductive organs" due to birth defects or surgery". ${ }^{108}$

The (B) item on Escaping...'s rap sheet is that I have "set out to disprove" "the traditional sex/gender distinction", to no avail. Somewhat puzzlingly, according to Dembroff I in effect make something like this traditional distinction myself, "albeit in a confused way", when I say that the categories female and male are both biological and "socially significant". ${ }^{109}$ (Dembroff never explains why this is confused.)

Here is an early version of the sex/gender distinction, from the British sociologist Ann Oakley:

[There is] a crucial distinction it is necessary to make in our thinking about male and female roles - the distinction between 'sex' and 'gender'. 'Sex' is a word that refers to the biological differences between male and female: the visible difference in genitalia, the related difference in procreative function. 'Gender' however is a matter of culture: it refers to the social classification into 'masculine' and 'feminine'. ${ }^{110}$

There is surely a distinction here, so setting out to "disprove" it is bound to end in tears. I had no such quixotic ambition, and there is no hint to the contrary in Are women...? What I did set out to disprove was another version of the sex/gender distinction, the one prevalent in contemporary philosophy, on which there is a distinction between "human females and males" and "women and men". 111

The (B) charge is incorrect, then. What about (C), the complaint that I have failed "to show that sex categories are not, in the relevant and interesting sense, social categories"? Are women...? already makes the (obvious) point that female and male are socially significant categories. This is undeniably interesting. It is also undeniably irrelevant to the aims of Are women...? So what is the problem supposed to be? It seems to be this: Escaping...'s discussion of (C) leads to something that does look like an objection. According to Dembroff, I take:

$\left(\mathrm{A}^{*}\right)$ adult human female and adult human male to be universal, stable, and discrete categories of sex traits, where $\left(B^{*}\right)$ a single set of sex traits [is] shared among all

106 Escaping..., 996.

107 See Are women...?, 3793.

108 lbid., 3791, n. 14.

109 Escaping..., 997.

110 Ann Oakley, Sex, Gender, and Society (London: Maurice Temple Smith, 1972), 21-2; page reference to the 2016 Routledge reprint. Oakley took this distinction from the UCLA psychiatrist Robert Stoller; see Stoller, Sex and Gender: on the development of masculinity and femininity (New York: Science House, 1968).

111 Are women..., 3784, quoting Mari Mikkola, The Wrong of Injustice: dehumanization and its role in feminist philosophy (Oxford: Oxford University Press, 2016), 23. This version of the sex/gender distinction can be found in Oakley too (Sex, Gender, and Society, 115). For a recent paper devoted entirely to it, see Bogardus, "Evaluating arguments for the sex/gender distinction". 
women, and where $\left(C^{*}\right)$ these categories can be explained without reference to cultural ideologies. ${ }^{112}$

Unfortunately for me, "Each of these claims is false". ${ }^{113}$ I am not completely sure what everything in this quoted passage means, but for safety's sake it should not go unexamined.

Dembroff begins the argument by trying to establish the falsity of $\left(A^{*}\right)$ : "there are no such stable, discrete, and exhaustive categories of sex traits" like adult human female. (Presumably "exhaustive" is supposed to be equivalent to "universal"; why Dembroff thinks adult human female is a sex trait rather than a developmental or species trait is obscure.) A quotation from the historian Joanne Meyerowitz is supposed to "[make] this point clearly":

[L]ike gender and sexuality, biological sex has a history. Humans have imagined it differently at different times and in different places. European and American scientists once envisioned sex as a hierarchy of similar beings in which female stood as an inferior version of male. With the Enlightenment of the late eighteenth century, though, they increasingly wrote of two sexes, distinct and opposite. Female less often appeared as a paler copy of male and more often as distinctly different and complementary. ${ }^{114}$

But the quotation simply says that accounts of "biological sex" have varied widely over human history. The details are fascinating, but the basic idea applies to almost anything that humans have been talking and thinking about for millennia, like water, lightning, and the heavens. To put Meyerowitz's point more whiggishly, we know vastly more about sex than Aristotle. The only things that changed were our knowledge and beliefs about sex, not sex itself. (If Dembroff intends to be using 'category' in the sense it has in Are women...?, categories are anyway not the kind of thing that can be "stable" or "unstable".)

The subsequent paragraph of Escaping... appeals to Meyerowitz again: "sexologists turned from "the visible realm of genitals to the microscopic gaze" to embark on a still ongoing "elusive quest" to find stable grounds for binary, exhaustive sex categorization". ${ }^{115}$ (Never mind that Meyerowitz is more charitably interpreted as talking about biomedical scientists, not "sexologists".) The paragraph also mentions that "the International Olympic Committee stipulated categories of "sport sex"'; naturally, in different social conditions, the IOC might have stipulated differently. Dembroff erroneously concludes that no "single, fixed category answers to "the" category adult human female". ${ }^{116}$ The IOC's task is to determine who counts as female for the purposes of fair competition, while taking into account the interests of all parties. That is by no means the same as determining who is female.

Next, Escaping... tries to establish $\left(\mathrm{B}^{*}\right)$, that there is no single "sex trait" that all women share. Since adult human female is taken to be a "sex trait", if $\left(\mathrm{B}^{*}\right)$ is correct AHF is false. In support of $\left(B^{*}\right)$ Dembroff quotes an impressionistic passage from Katrina Karkazis, a cultural anthropologist. According to Karkazis, "If [biological traits $M$ and $F$ ] were understood as the essence of sex [male and female, respectively], women ...

\footnotetext{
112 lbid., 997-98, labels added.

113 Ibid., 998.

114 Joanne J. Meyerowitz, How Sex Changed: a history of transsexuality in the United States (Cambridge, MA: Harvard University Press, 2004), 21-2; quoted in Escaping ... , 998, Dembroff's emphasis.

115 Escaping ... , 998; quotes within the quotation from Meyerowitz, How Sex Changed, 2.

116 Ibid., 998.
} 
who had [trait $M$ but not $F$ ] were men. This seemed illogical, so scientists proposed yet other traits". ${ }^{117}$ That seems quite sensible! ${ }^{118}$ The problem is supposedly that the other traits were no better; as Dembroff puts it, "a century-long search for such traits has come up empty". 119

The quoted passage does not actually support $\left(\mathrm{B}^{*}\right)$, that not even the "sex trait" adult human female is common to all women. Instead, what it does support is something quite different, that (in Karkazis's phrase) there is no "single, definitive biological indicator" of sex. That is, scientists have been searching for something that unifies the females, and something else that unifies the males, and all the plausible candidates have been found wanting. Female and male have turned out to be like tree or bug in the "small insect-like creature" sense, superficial folk categories that biologists have little theoretical use for. ${ }^{120}$ Pretend that this is right. Does it show that AHF is false? No: AHF says nothing about whether female cuts nature at the joints. Does it show that woman is a social category? No: tree and bug are not social categories. Does it show that female is not a biological category in the very demanding sense in which tree and bug are not biological categories? Yes, but as noted above, that is not the issue. ${ }^{121}$

As to $\left(C^{*}\right)$, that categories of "sex traits" cannot "be explained without reference to cultural ideologies", Escaping... does not "rehash the many detailed arguments", gesturing instead at a "plethora of books and articles". ${ }^{122}$ (I completely agree with the claim of quantity. ${ }^{123}$ ) We need not investigate this further, but it is worth noting that Escaping ... 's citations have a curious omission. Cultural anthropology is a worthy discipline, no doubt, but what about biology? If you want to know what sex is, why not consult a few works by biologists, or philosophers of biology? ${ }^{124}$ Just a suggestion.

117 Katrina Karkazis, "The misuses of "biological sex"”, The Lancet 394 (2019): 1898-9, 1898. The quotation in Escaping ... is slightly inaccurate.

118 The full quotation is this: "If gonads were understood as the essence of sex, women who were phenotypically female but who had testes were men. This seemed illogical, so scientists proposed yet other traits." It is not clear what "scientists" Karkazis is referring to. She may have in mind the early twentieth century British gynecologist William Blair-Bell (see Alice Domurat Dreger, Hermaphrodites and the Medical Invention of Sex (Cambridge, MA: Harvard University Press, 1998), 158-66; cited in Katrina Karkazis, Fixing Sex: intersex, medical authority, and lived experience (Durham, NC: Duke University Press, 2008), 40). In any case, the quotation gives a somewhat misleading impression of consensus (see, e.g., John Money, "Hermaphroditism, gender and precocity in hyperadrenocorticism: psychologic findings", Bulletin of the Johns Hopkins Hospital 96 (1955): 253-64, 254; B. Hammar, M. Michowitz and M. Solowiejczyk, "Testicular feminization syndrome", The American Surgeon 46 (1980): 457-60, 458).

119 Escaping..., 998.

120 On tree, see John Dupré, “Natural kinds and biological taxa”, Philosophical Review 90 (1981): 66-90, 80.

121 For an extensive discussion of categories in the natural and social sciences, see Muhammad Ali Khalidi, Natural Categories and Human Kinds (Cambridge: Cambridge University Press, 2013). (That book uses 'kind' in place of Are women ... ?'s 'category'-see 5.)

122 Escaping ..., 1000.

123 Cf. Karkazis: "sex ... is culturally contingent ... [it] is not a static, discrete, or even strictly biological characteristic that exists prior to the relations and practices that produce it" ("The misuses of "biological sex"', 1898). This is a representative indication of the quality of Dembroff's sources.

124 Biologists: Joan Roughgarden, Evolution's Rainbow: diversity, gender, and sexuality in nature and people (Los Angeles: University of California Press, 2004), 26; Geoff A. Parker, "The origin and maintenance of two sexes (anisogamy), and their gamete sizes by gamete competition", in The Evolution of Anisogamy: a fundamental phenomenon underlying sexual selection, ed. Tatsuya Togashi and Paul Alan Cox (Cambridge: Cambridge University Press, 2011); Leo Beukeboom and Nicolas Perrin, The Evolution of Sex Determination (Oxford: Oxford University Press, 2014), chap. 1; Douglas J. Futuyama and Mark Kirkpatrick, Evolution (Sunderland, MA: Sinauer, 2017), 249. Philosophers of biology: John Dupré, The Disorder of Things: Metaphysical foundations of the disunity of science (Cambridge, MA: Harvard 


\section{Motives}

Finally, we reach the last part of Escaping.... In accordance with the new norms of scholarship that Dembroff seems to be following, the hidden motives of the present writer are exposed to the light. The "larger methodological and ethical problems" of Are women...? are scrutinized. ${ }^{125}$ The rhetorical needle of the previous sections, already quivering around 10 , is ramped up to 11.

The larger problems are these. I assume that "there are two universal genders, every person immutably has one, and all this is vindicated by science". I "cite the testimony of trans persons only for the purpose of undermining these persons' self-understanding, or for pitting them against other trans persons". I "sweepingly dismiss cultures with nonbinary gender systems in a footnote". I "conjure a fictional intersex variation for the purpose of arguing that, no matter how much an intersex person looks, behaves, or claims to be a woman, they are not one". 126

I am afraid I have already have overused 'incorrect', but let me stick to the word for uniformity. All these claims are incorrect. (One caveat: I am not sure what Dembroff means by the phrase 'universal gender'.) My reasons for citing the testimony of transgender women are right on the surface. ${ }^{127}$ The pertinent footnote contains no dismissal of cultures with a "third gender"; a thousand genders can bloom, as far as Are women...? is concerned. ${ }^{128}$ I make use of a fictional case of a person who is neither male nor female for reasons that are also on the surface. ${ }^{129}$ The contrary charges are an artefact of Dembroff's hermeneutical approach of reading between the lines rather than actually reading the lines. I should perhaps emphasize that I have absolutely no interest in gratuitously dragging transgender people or people with DSDs into philosophical arguments. ${ }^{130}$ They figure in Are women...? only because some of my opponents' arguments appeal to them. ${ }^{131}$

University Press, 1995), chap. 3; Laura Franklin-Hall, "The animal sexes as historical explanatory kinds", in Current Controversies in Philosophy of Science, ed. Shamik Dasgupta and Brad Weslake (London: Routledge, 2020); Muhammad Ali Khalidi, "Are sexes natural kinds?", in Current Controversies in Philosophy of Science, ed. Shamik Dasgupta and Brad Weslake (London: Routledge, 2020).

125 Escaping ..., 1000

126 lbid., 1000-1.

127 See Are women...?, 3798-9

128 See ibid., 3792, n. 16. About that footnote, Dembroff writes: "Byrne appeals to linguistic translation (from a language with nonbinary gender terms to one with only binary gender terms) to undermine the legitimacy of nonbinary categories" (Escaping..., 995, n. 52). I do not know what Dembroff means by 'legitimacy', or why the footnote is said to use "cherry-picked quotations" (995), but there is a hint that the translations aren't accurate because English has "only binary gender terms", or at least not a rich enough stock of non-binary gender terms ('nonbinary' is a word of English). Consider one third gender I mention, the Samoan fa'afafine. According to Paul Vasey (an expert who has studied the fa'afafine for many years), "Translated literally, fa'afafine means "in the manner of a woman"” (Paul L. Vasey and Nancy H. Bartlett, "What can the Samoan "fa'afafine" teach us about the Western concept of gender identity disorder in childhood?", Perspectives in Biology and Medicine 50 (2007): 481-90, 484). Is Vasey wrong about that? If he isn't, why think there is an insuperable obstacle to translation elsewhere?

129 See Are women ... ?, 3793. Taken literally, Dembroff is attributing to me the insane view that no person with an intersex condition who claims to be a woman is one. It is possible that Dembroff has been misled by the 'intersex' terminology, but this is speculation on my part.

130 DSDs: Disorders of Sex Development. See Peter A. Lee et al., "Global disorders of sex development update since 2006: perceptions, approach and care", Hormone Research in Paediatrics 85 (2016): 158-80.

131 As Are women ... ? recounts, feminist philosophers have taken a keen interest in transsexuality (3797). 
Dembroff ends by confidently proclaiming that I am trying to vindicate a political slogan, 'Women are adult human females'. Evidently, the allegation is that I am in sympathy with the aims of an "anti-trans" movement. ${ }^{132}$ In a footnote, Dembroff says that it is "particularly obvious that Byrne is defending a political slogan", apparently on the ground that the Oxford English Dictionary entry does not contain 'adult human female'. ${ }^{133}$ (Merriam-Websters is also given as another example.) Instead, the OED entry is 'adult female human being', although the footnote does not mention that. Dembroff's reasoning is not explicit, but might be this: the obvious explanation of why I chose 'adult human female' instead of 'adult female human' is that I intended to signal my support of those who deploy 'Woman are adult human females' to "undermine civic rights and respect for trans persons". ${ }^{134}$

After all, what other explanation could there possibly be? Well, Are women...? does say that an "eminently desirable and feasible goal is for trans women (and men) to be accepted by society and live in peace and dignity". 135 And 'adult human female' is a perfectly ordinary phrase. It gets more significantly more hits on Google than 'adult female human', restricting the search to the period before it became part of a slogan. It is-or rather, was - the definition of 'woman' in the Google Dictionary. ${ }^{136}$ In any case, can it seriously be imagined that I would have been let off the hook if I had reversed 'human' and 'female'? One could equally well argue that I chose the alternative formulation to give myself plausible deniability. ${ }^{137}$

According to Escaping...'s abstract, 'Women are adult human females' appears on "billboards, pamphlets, and anti-trans online forums", but no citations are provided describing where this occurred, or why. Later, the sentence is said to be associated with "conservative groups". ${ }^{138}$ To my knowledge, 'Woman are adult human females' has appeared on no billboard. However, 'woman womən noun adult human female' was a billboard slogan in the UK after the government proposed reforms to the 2004 Gender Recognition Act (now shelved), so this must be the political context to which Dembroff is alluding. ${ }^{139}$

132 Escaping..., 983-84.

133 Ibid., 988-89, n. 24; emphasis added.

134 lbid., 1001.

135 Are women ... ? 3800

136 Sometime after April 20, 2020, the definition was changed to 'adult female human being'. 'Adult human female' first appears in drafts from which Are women ... ? was derived in early 2017. (I had consulted the OED entry, which appears on a slide in a talk given in early 2018 , but attached no significance to the difference in wording.) The slogan (in its dictionary version-see below) did not begin to catch on until later in 2018.

'Adult human female/male' are arguably more natural constructions than 'adult female/male human' because they fit the Aristotelean order of genus + differentia: adult human (genus), female/male (differentia).

137 Moreover, radical feminists sometimes use the alternative, as well as 'female adult human' (see, e.g., Julia Beck, "Testimony before the Baltimore LGBTQ Commission Law and Policy Committee," 2018, excerpted at: https://www.womensliberationfront.org/news/you-might-as-well-call-it-the-gbtqcommission-lone-lesbian-pushed-off-baltimore-committee).

138 Escaping..., 993.

139 Neither the dictionary slogan nor 'Women are adult human females' has gained traction in the US. In 2019, the socially conservative Heritage Foundation hosted a critical discussion about the US Equality Act, which would add gender identity to the list of federally protected characteristics. The panel was moderated by Ryan T. Anderson, a devout Catholic and opponent of same-sex marriage, and featured members of the Women's Liberation Front (WoLF), a group of radical feminists "Dedicated to the total liberation of women". The WoLF website (womensliberationfront.org, searched May 2020) has some scattered occurrences of 'wom(e/a)n' combined with 'adult human female(s)' but none of 'Women are adult human females' or the dictionary slogan, and Anderson's book When Harry Became Sally: responding to 
Some corrections are needed. It was the center-right Conservative government under Prime Minister Theresa May which proposed changing the GRA; this would have made it considerably easier for transgender people to be legally recognized as their "acquired gender". A government consultation document was published in July 2018, and opposition came from various grassroots women's groups, with significant representation from the trade union and labour movement. What is now the main group, Woman's Place UK, did not adopt the dictionary slogan. Two billboards displaying it were put up by the founder of another group, Standing for Women, in September and October of 2018; the first was quickly taken down by the billboard company and the second, incongruously placed above a sex shop, had little impact. (The dictionary slogan also appeared on T-shirts, stickers, and postcards.) There is no doubt that the slogan and its relatives are sometimes wielded by those with ill-will towards transgender people, but they are also used by those who agree with the Telegraph journalist Diana Thomas: "The rightful struggle for recognition and respect for our identity should not require everyone else to redefine their entire concept of what it means to be male or female". ${ }^{140}$ I am sure that the socialist feminists Linda Bellos and Lucy Masoud would be surprised to discover that they are part of a vast right-wing conspiracy. ${ }^{141}$ The point is not to pick sides. But if one is going to pick sides, it is important to characterize the sides correctly. ${ }^{142,143}$

Acknowledgments: Many thanks to Ray Blanchard, Tomas Bogardus, George Christofi, Holly Lawford-Smith, Kathleen Stock, three anonymous referees for The Journal of Controversial Ideas, and a few anonymous others. I would also like to thank Stew Cohen, the former Editor-in-Chief of Philosophical Studies, for encouraging me to write this paper.

the transgender moment (New York: Encounter Books, 2018) does not contain 'adult human female(s)' (or 'adult female human(s)').

140 Thomas, "I'm not going to turn into ... "; see Section 3 above.

141 See Claire Heuchan, "If feminist Linda Bellos is seen as a risk, progressive politics has lost its way", Guardian, October 6, 2017, https://www.theguardian.com/commentisfree/2017/oct/06/feministlinda-bellos-women-trans-male-violence, and Lucy Masoud, "Talk at Women's Place UK", February 27, 2018, https://youtu.be/wwkEO8HQ8Hw.

${ }^{142}$ For those interested in learning more about the UK context, I recommend a series of articles in The Economist, featuring a variety of perspectives (Helen Joyce, "After two weeks, our transgender identity series comes to a close", The Economist, July 17, 2018, https://www.economist.com/open-future/ 2018/07/17/after-two-weeks-our-transgender-identity-series-comes-to-a-close), James Kirkup's articles in The Spectator (e.g., "Can we have an honest debate about gender?", The Spectator, February 7, 2018, https://www.spectator.co.uk/article/can-we-have-an-honest-debate-about-gender-; "How women won the war against gender 'self-ID'”, The Spectator, September 22, 2020, https://www.spectator.co. uk/article/how-women-won-the-war-against-gender-self-id-), and an interview with the YouTuber (and transgender woman), Rose of Dawn (Francis Foster, Konstantin Kisin, and Rose of Dawn, "Interview with Rose of Dawn", Triggernometry, December 15, 2019, https://youtu.be/ak8v1LxdavY).

143 In 2019, the employment contract of a UK tax expert, Maya Forstater, was not renewed because of Forstater's expressed views on the gender debate (see Kathleen Stock, "Maya Forstater says that women are adult human females. Does this count as a "philosophical belief"?", The Article May 10 (2019), https://www.thearticle.com/maya-forstater-says-that-women-are-adult-human-females-doesthis-count-as-a-philosophical-belief). 'Women are adult human females' appears in Forstater's testimony to an employment tribunal (Maya Forstater, "Claimant's witness statement", Medium, November 22, 2019, https://medium.com/@MForstater/claimants-witness-statement-abe3e8073b41). Citing this testimony, Dembroff claims that "a number of high-profile court briefings opposing trans rights in both the US and the UK cite blog posts by philosophers such as Kathleen Stock and Alex Byrne as evidence that trans persons are dangerous and deluded" (Robin Dembroff, "Cisgender commonsense and philosophy's transgender trouble”, TSQ: Transgender Studies Quarterly (2020): 399-406, 400, emphasis added). As can readily be checked by following the previous link (which Dembroff supplies) and searching for 'Stock' and 'Byrne', the citations are not to blog posts and (like Forstater's testimony as a whole) have absolutely nothing to do with the emphasized phrase. 